\title{
Does the wait for lumbar degenerative spinal stenosis surgery have a detrimental effect on patient outcomes? A prospective observational study
}

\author{
Christopher S. Bailey MD, Kevin R. Gurr MD, Stewart I. Bailey MD, David Taylor MD, \\ M. Patricia Rosas-Arellano MD PhD, Corinne Tallon BSc, Yves Bureau PhD, Jennifer C. Urquhart PhD
}

Abstract

Background: Waits for elective spine surgery are common in Canada. We examined whether a prolonged wait for surgery for lumbar degenerative spinal stenosis was detrimental to outcome.

Methods: In this prospective observational study, we enrolled 166 consecutive patients referred to our centre for treatment of lumbar degenerative spinal stenosis between 2006 and 2010. Outcome measures were assessed at referral, preoperatively and until 24 months postoperatively. Primary outcome measures were the physical and mental component summary scores of the 36-Item ShortForm Health Survey and the Oswestry Disability Index. Secondary outcome measures included the symptom severity scale of the Zurich Claudication Questionnaire, a numeric rating scale for back and leg pain, and patient satisfaction with treatment. Wait time was defined as the time from referral to surgery.

Results: The follow-up rate at 2 years was $85 \%$. The median wait time was 349 days. All health-related quality of life measures deteriorated during the waiting period, but there was no significant correlation between wait time and magnitude of the change in outcome measure. At 6 months postoperatively, the Pearson correlation was significantly positive between wait time and change in disability $(r=0.223)$, Zurich Claudication Questionnaire score $(r=0.2)$ and leg pain score $(r=0.221)$. At 12 months, the correlation remained significant for change in disability $(r=0.205)$ and was significant for change in mental well-being $(r=-0.224)$. At 12 months, patients with a shorter wait ( $\leq 12$ months) showed greater improvement in mental well-being (mean difference in change [and 95\% confidence interval (Cl)] 5.7 [1.49.9]) and decrease in disability $(-9.3[95 \% \mathrm{Cl}-15.1$ to -3.6$])$ and leg pain $(-1.6[95 \% \mathrm{Cl}-3.0$ to -0.3$])$. There were no statistically significant differences in outcome or patient satisfaction with treatment between those with shorter and longer waits at 24 months.

Interpretation: Patients awaiting spinal surgery experienced deterioration in health-related quality of life irrespective of the length of wait time. However, longer waits were associated with a delay in recovery during the first year after surgery.

\footnotetext{
r umbar degenerative spinal stenosis has a profound negative effect on function and quality of life. The preoperative health-related quality of life (HRQoL) outcomes for this disorder are poorer than those for other conditions, such as congestive heart failure, chronic obstructive pulmonary disease and cancer, and for frequently performed orthopedic procedures. ${ }^{1-3}$ Lumbar degenerative spinal stenosis is the leading indication for lumbar spinal surgery in patients over 65 years of age. ${ }^{1,4}$ Surgery is recognized to be superior to nonoperative care for the first 4 years after surgery; however, this advantage may diminish in the long term. ${ }^{4-8}$ The improvement in quality of life following surgery compares favourably to that achieved following total hip or knee arthroplasty, recognized as the gold standard in orthopedic surgery for achieving pain reduction and improvement in function and quality of life. ${ }^{3,9,10}$
}

In Canada, the wait time for spinal procedures is long, with a perceived detrimental effect on outcome and satisfaction. ${ }^{11}$ Furthermore, with the aging of the population in industrialized countries, wait times may become longer over time. The effect of these prolonged wait times on HRQoL and postoperative outcome for patients awaiting spinal stenosis is unknown. Our primary objective was to determine whether longer waits to

Competing interests: None declared.

This article has been peer reviewed.

Correspondence to: Christopher Bailey, Chris.Bailey@Ihsc.on.ca CMAJ Open 2016. DOI:10.9778/cmajo.20150001 
lumbar degenerative spinal stenosis surgery were associated with poorer preoperative and postoperative HRQoL. Our secondary objective was to determine the effect of wait time on patients' satisfaction with treatment.

\section{Methods}

\section{Setting and population}

We conducted a prospective observational study involving patients referred to 1 of 3 fellowship-trained orthopedic spine surgeons at the London Spine Centre, London Health Sciences Centre, London, Ont., for treatment of lumbar degenerative spinal stenosis. The study was approved by our institutional research ethics board. We screened consecutive referrals for eligibility between February 2006 and June 2010. The inclusion criteria were neurogenic claudication or radiculopathy secondary to central or lateral recess stenosis between L1 and S1 confirmed by computed tomography or magnetic resonance imaging, and patient consent for surgical treatment. Patients were excluded if the stenosis was not degenerative (i.e., traumatic stenosis from a pathologic fracture); if they had inflammatory spine disease, severe or progressive neurological deficit requiring urgent surgery, cancer or previous lumbar surgery; if they were unable to complete the questionnaire or provide follow-up (i.e., no permanent address, substance abuse, interfering psychiatric illness); or if they were pregnant.

\section{Design}

Patients who met the inclusion criteria were mailed a study information letter, an outcome questionnaire and the date of their initial consultation visit. We assigned the initial consultation visit according to the date the referral was received, with no formalized prioritization system. Patients returned the questionnaire by mail in a prepaid addressed envelope. At the initial consultation visit, the spine surgeon reassessed patients for eligibility using criteria that could not be assessed on the initial referral (Figure 1). We invited all eligible patients to enter the study and obtained written informed consent from those who agreed to participate. We maintained a $\log$ of the names of patients who were excluded or did not wish to participate. Patients waited for surgery on the individual surgeon's wait list. The 3 surgeons had equal access to operating room time.

\section{Measures}

We collected outcome measures at the initial referral (by mail), at the initial consultation with the surgeon, immediately before surgery, and 6, 12 and 24 months postoperatively. Primary outcome measures included the physical and mental component summary scores of the 36-Item Short-Form Health Survey (SF-36) and the Oswestry Disability Index. Secondary outcome measures included the symptom severity scale of the Zurich Claudication Questionnaire, a numeric rating scale for back and leg pain, and patient satisfaction with treatment. The SF-36 is a generic, multidimensional self-report health questionnaire that has been validated among patients undergoing spine surgery. ${ }^{12}$ For its physical and mental component sum- mary scores, higher scores imply better functioning. The Oswestry Disability Index evaluates physical disability secondary to back and leg pain, ${ }^{13}$ and the Zurich Claudication Questionnaire evaluates severity of spinal stenosis symptoms. ${ }^{14}$ With both measures, a higher score denotes increased disability. The numeric rating scale for back and leg pain ranges from 0 to 10 , with lower scores indicating less severe symptoms. ${ }^{15}$ We initially assessed patient satisfaction with treatment using a scale from 0 (unsatisfied) to 7 (completely satisfied), but for the analysis a score of 6 or 7 represented satisfied.

\section{Analysis}

We defined a shorter versus a longer wait according to the median wait time from referral to surgery. We used $\chi^{2}$ tests and unpaired $t$ tests to compare wait times, patient characteristics, patient satisfaction scores and outcome scores, and to compare participants with missing data to those who participated in all visits. We conducted a Pearson product-moment correlation to assess the correlation between HRQoL scores at referral and wait time, and HRQoL scores immediately preoperatively and wait time. We also performed a Pearson correlation to assess change in mean HRQoL scores from referral to preoperative assessment by wait time, adjusting for age, surgeon, duration of symptoms and type of surgery. To control for the values of interest, the covariates were regressed on the outcome variable of interest, and the residual scores were then correlated (Pearson) with the wait scores. In addition, we conducted a Pearson correlation to assess the difference in change in mean preoperative to postoperative (6, 12 and 24 months) assessment by wait time, adjusting for age, surgeon, duration of symptoms, type of surgery and baseline outcome value. Finally, we conducted an analysis of covariance to quantify the difference in change between the 2 wait time groups in mean preoperative to postoperative assessment, adjusting for age, surgeon, duration of symptoms, type of surgery and baseline outcome value. We considered $p$ values $<0.05$ to be statistically significant.

\section{Results}

A total of 166 patients were enrolled from the 1126 referrals considered during screening (Figure 1). The most frequent reasons for ineligibility were nonoperative management (312 patients $[27.7 \%]$ ) and improper spinal stenosis diagnosis/ referral (198 [17.6\%]).

The 166 patients had a mean age of 66.2 (SD 9.0) years and mean body mass index of 29.0 (SD 5.0) (Table 1). Most were retired and had at least 1 comorbid condition. Half of the patients (84 [50.6\%]) had classic neurogenic claudication, and most (124 [74.7\%]) had back pain symptoms. The patients had experienced symptoms for a median duration of 24 months (range 6-210 months) at the time of initial consultation with the spine surgeon. Most patients had central and lateral recess stenosis (94 [56.6\%]), stenosis at L4-L5 (146 [88.0\%]) and spondylolisthesis (96 [57.8\%]).

Most participants (136 [81.9\%]) underwent decompression and instrumented fusion (Table 2). At 2 years, 16 patients 
$(9.6 \%)$ required a second procedure; fewer than half of the procedures were for recurrent symptoms (stenosis at same or adjacent level).

The follow-up rate was $85 \%$ or higher for each visit. $\mathrm{Pa}-$ tients with missed visits were similar to the rest of the cohort except that they were more likely to be unemployed owing to their back condition $(16.7 \% \mathrm{v} .4 .5 \%, p=0.02)$ and to have less severe leg pain at referral (mean score 7.7 [SD 1.7] v. 8.4 [1.6], $p=0.04)$ (data not shown).

The mean and median wait times for surgery are shown in Table 3. For our analyses, we categorized wait time into shorter and longer using the median wait time of 12 months as the distinction.

The baseline characteristics of the patients with shorter waits $(n=94)$ were similar to those of the patients with longer waits $(n=72)$ (Table 1$)$. More patients in the longer-wait group than in the shorter-wait group underwent a multilevel fusion procedure (22 [30.6\%] v. 14 [14.9\%], $p=0.02$ ) (Table 2 ). The median postoperative hospital stay was 4 days (range 1-18 days), with no difference between the 2 groups $(p=0.6)$. The 2 groups had similar rates of complications, reoperation and death (Table 2).

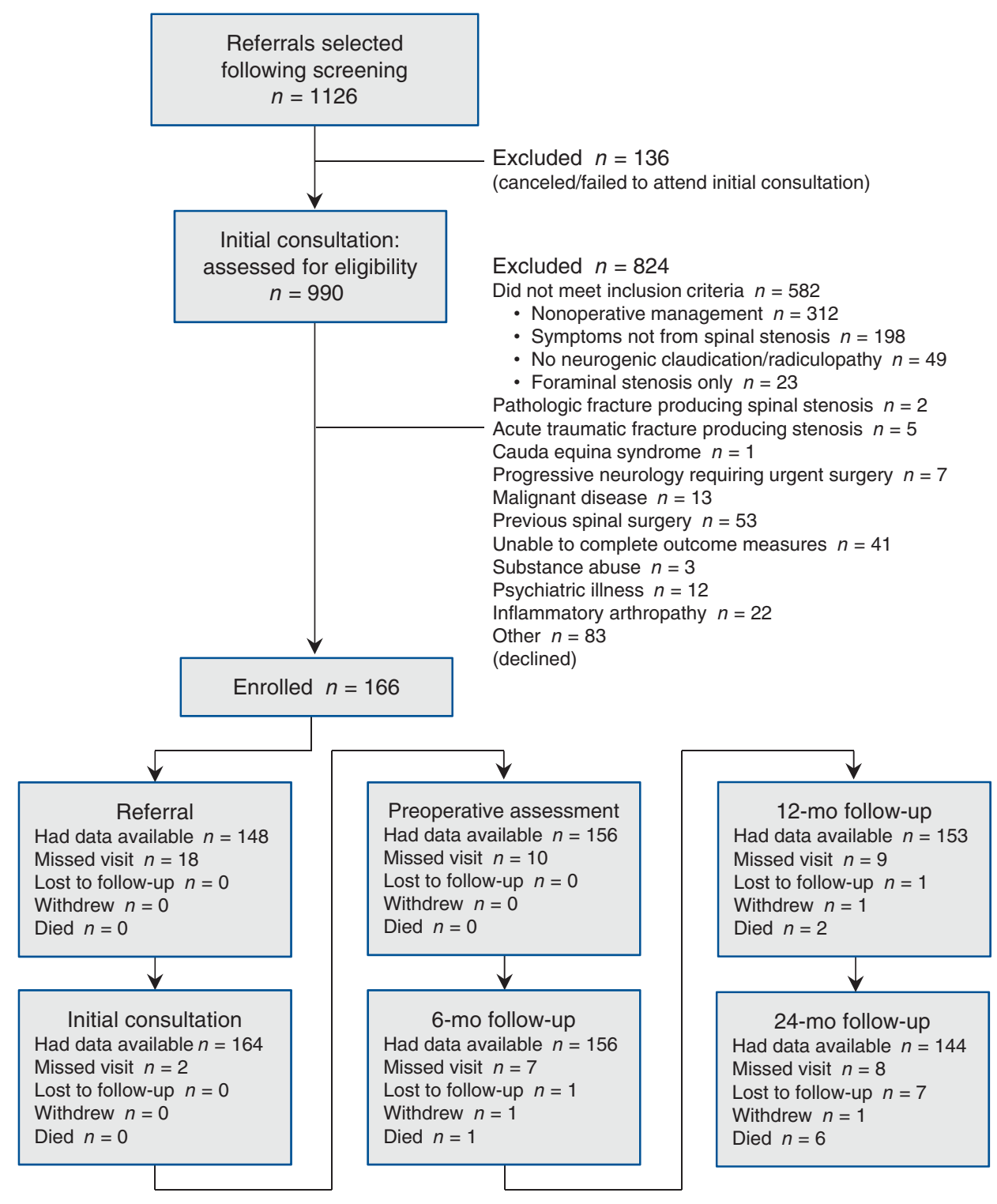

Figure 1: Flow diagram of the selection of study participants and follow-up. Numbers after "Enrolled" are cumulative. 
Table 1: Baseline characteristics of patients with lumbar degenerative spinal stenosis, by wait time

\begin{tabular}{|c|c|c|c|c|}
\hline \multirow[b]{2}{*}{ Characteristic } & \multirow{2}{*}{$\begin{array}{c}\text { Total cohort, no. }(\%) \text { of } \\
\text { patients* } \\
n=166\end{array}$} & \multicolumn{2}{|c|}{ Wait time†; no. (\%) of patients* } & \multirow[b]{2}{*}{$p$ value } \\
\hline & & $\begin{array}{c}\text { Shorter }(\leq 12 \mathrm{mo}) \\
\quad n=94\end{array}$ & $\begin{array}{l}\text { Longer (> } 12 \mathrm{mo}) \\
\quad n=72\end{array}$ & \\
\hline Age, yr, mean \pm SD & $66.2 \pm 9.0$ & $66.1 \pm 8.7$ & $66.3 \pm 9.3$ & 0.8 \\
\hline $\mathrm{BMI}$, mean $\pm \mathrm{SD}$ & $29.0 \pm 5.0$ & $28.7 \pm 4.5$ & $29.4 \pm 5.6$ & 0.4 \\
\hline Women & $79(47.6)$ & $43(45.7)$ & $36(50.0)$ & 0.6 \\
\hline \multicolumn{5}{|l|}{ Smoking status } \\
\hline Never or no longer & $145(87.3)$ & $83(88.3)$ & $62(86.1)$ & \multirow[t]{2}{*}{0.7} \\
\hline Current & $21(12.7)$ & $11(11.7)$ & $10(13.9)$ & \\
\hline \multicolumn{5}{|l|}{ Employment status } \\
\hline Unemployed (related to back pain) & $14(8.4)$ & $10(10.6)$ & $4(5.6)$ & \multirow[t]{5}{*}{0.5} \\
\hline Unemployed (unrelated to back pain) & $2(1.2)$ & $1(1.1)$ & $1(1.4)$ & \\
\hline Employed & $39(23.5)$ & $18(19.1)$ & $21(29.2)$ & \\
\hline Retired & $106(63.9)$ & $62(66.0)$ & $44(61.1)$ & \\
\hline Homemaker & $5(3.0)$ & $3(3.2)$ & $2(2.8)$ & \\
\hline \multicolumn{5}{|l|}{ Comorbid condition $\ddagger$} \\
\hline None & $33(19.9)$ & $21(22.3)$ & $12(16.7)$ & 0.4 \\
\hline Hypertension & $87(52.4)$ & $44(46.8)$ & $43(59.7)$ & 0.1 \\
\hline Diabetes mellitus & $25(15.1)$ & $14(14.9)$ & $11(15.3)$ & 0.9 \\
\hline Osteoporosis & $2(1.2)$ & $1(1.1)$ & $1(1.4)$ & 0.8 \\
\hline Heart disorder & 27 (16.3) & $15(16.0)$ & $12(16.7)$ & 0.9 \\
\hline Stomach disorder & $21(12.6)$ & $13(13.8)$ & $8(11.1)$ & 0.6 \\
\hline Bowel or intestinal disorder & $2(1.2)$ & $1(1.1)$ & $1(1.4)$ & 0.8 \\
\hline Depression & $7(4.2)$ & $5(5.3)$ & $2(2.8)$ & 0.4 \\
\hline Joint disorder & $25(15.1)$ & $13(13.8)$ & $12(16.7)$ & 0.6 \\
\hline Thyroid disorder & $15(9.0)$ & $9(9.6)$ & $6(8.3)$ & 0.8 \\
\hline Other & $31(18.7)$ & $15(16.0)$ & $16(22.2)$ & 0.3 \\
\hline Unknown & $9(5.4)$ & $5(5.3)$ & $4(5.6)$ & 0.9 \\
\hline \multicolumn{5}{|l|}{ Neurological diagnosis } \\
\hline Claudication & $84(50.6)$ & $48(51.2)$ & $36(50.0)$ & \multirow[t]{3}{*}{0.6} \\
\hline Radiculopathy & $10(6.0)$ & $7(7.4)$ & $3(4.2)$ & \\
\hline Both & $72(43.4)$ & $39(41.5)$ & $33(45.8)$ & \\
\hline \multicolumn{5}{|l|}{ Primary complaint } \\
\hline Neurological & $42(25.3)$ & $28(29.8)$ & $14(19.4)$ & \multirow[t]{2}{*}{0.1} \\
\hline Neurological and mechanical back pain & $124(74.7)$ & $66(70.2)$ & $58(80.5)$ & \\
\hline $\begin{array}{l}\text { Duration of symptoms from time of onset to initial } \\
\text { consultation with surgeon, mo, median (range) }\end{array}$ & $24(6-210)$ & $24(6-150)$ & $30(6-210)$ & 0.2 \\
\hline \multicolumn{5}{|l|}{ Location of stenosis } \\
\hline Central and lateral recess & $94(56.6)$ & $55(58.5)$ & $39(54.2)$ & \multirow[t]{4}{*}{0.2} \\
\hline Central, foraminal and lateral recess & $38(22.9)$ & $16(17.0)$ & $22(30.6)$ & \\
\hline Lateral recess and foraminal & $11(6.6)$ & $7(7.4)$ & $4(5.6)$ & \\
\hline Lateral recess & $23(13.9)$ & $16(17.0)$ & $7(9.7)$ & \\
\hline \multicolumn{5}{|l|}{ Level of stenosis $\ddagger$} \\
\hline L2-3 & $15(9.0)$ & $5(5.3)$ & $10(13.9)$ & 0.06 \\
\hline L3-4 & $59(35.5)$ & $30(31.9)$ & 29 (40.3) & 0.3 \\
\hline L4-5 & $146(88.0)$ & $81(86.2)$ & $65(90.3)$ & 0.4 \\
\hline L5-S1 & $17(10.2)$ & $6(6.4)$ & $11(15.3)$ & 0.06 \\
\hline \multicolumn{5}{|l|}{ No. of levels affected } \\
\hline 1 & $113(68.1)$ & $66(70.2)$ & $47(65.3)$ & \multirow[t]{2}{*}{0.5} \\
\hline$\geq 2$ & $53(31.9)$ & $28(29.8)$ & $25(34.7)$ & \\
\hline Spondylolisthesis & $96(57.8)$ & $55(58.5)$ & $41(56.9)$ & 0.8 \\
\hline $\begin{array}{l}\text { Note: } \mathrm{BMI}=\text { body mass index. } \\
{ }^{*} \text { Unless stated otherwise. } \\
\text { †Defined according to the median wait time from referral } \\
\ddagger \text { Some patients had more than } 1 \text { comorbid condition or }\end{array}$ & is. & & & \\
\hline
\end{tabular}




\section{Effect of wait time on preoperative function}

At referral, the SF-36 mental component summary score, Oswestry Disability Index score and leg pain score correlated significantly but weakly with wait time, indicating that patients with shorter waits had poorer mental health scores, more spine-specific disability and more severe leg pain than those with longer waits (Table 4). At the preoperative assessment, the SF-36 mental component summary score was again correlated significantly but weakly with wait time, indicating that patients with shorter waits were more likely to have a poorer mean score. The Oswestry Disability Index score, Zurich Claudication Questionnaire score and leg pain score had a significant positive correlation with wait time, which suggests that poorer outcomes correlated with longer wait times (Table 4).

No significant correlation was found between wait time and mean change in outcomes between referral and the preoperative assessment, adjusted for age, surgeon, duration of symptoms at consultation and type of surgery (Table 5). For both the shorter- and longer-wait groups, some deterioration occurred during the waiting period for all outcome measures. However, in keeping with the Pearson correlation, there was no evidence that the deterioration was affected by longer waits.

\section{Effect of wait time on postoperative outcome}

There was a weak significant positive correlation between wait time and improvement in outcome from the preoperative assessment to the 6-month assessment for the Oswestry Disability Index score, Zurich Claudication Questionnaire score and leg pain score (Table 6). The correlation remained significant but weak for Oswestry Disability Index score and was shown for SF-36 mental component summary score at 12 months. At 24 months there was no significant correlation between change in outcome and wait time. Comparisons between the 2 wait time groups of the mean difference in change from preoperatively to 6 and 12 months postoperatively showed that patients who had a shorter wait experienced greater gains in improvement on the SF-36 mental component summary score, Oswestry Disability Index score and leg pain score (Table 7). However, by 24 months there was no longer a difference.

\section{Effect of wait time on patient satisfaction}

There was no difference in patient satisfaction with treatment at the end of the preoperative waiting period between patients with shorter and longer waits $(6.8 \%$ v. $12.5 \%, p=0.4)$. At 6 months after surgery, most patients in both groups were satisfied with the outcome of their treatment $(89.4 \%$ of those in

Table 2: Surgical treatment and perioperative complications

\begin{tabular}{|c|c|c|c|c|}
\hline \multirow[b]{2}{*}{ Variable } & \multirow{2}{*}{$\begin{array}{c}\text { Total cohort, no. (\%) of } \\
\text { patients } \\
n=166\end{array}$} & \multicolumn{2}{|c|}{ Wait time; no. (\%) of patients ${ }^{\star}$} & \multirow[b]{2}{*}{$p$ value } \\
\hline & & $\begin{array}{c}\text { Shorter }(\leq 12 \mathrm{mo}) \\
\quad n=94\end{array}$ & $\begin{array}{c}\text { Longer (> } 12 \mathrm{mo}) \\
n=72\end{array}$ & \\
\hline \multicolumn{5}{|l|}{ Type of surgery } \\
\hline Decompression without fusion & $26(15.7)$ & $12(12.8)$ & $14(19.4)$ & 0.1 \\
\hline \multicolumn{5}{|l|}{ Decompression and fusion } \\
\hline Posterior instrumented fusion & $49(29.5)$ & $25(26.6)$ & $24(33.3)$ & \\
\hline Posterior interbody fusion & $87(52.4)$ & $53(56.4)$ & $34(47.2)$ & \\
\hline In situ fusion & $4(2.4)$ & $4(4.3)$ & $0(0.0)$ & \\
\hline Multilevel fusion & $35(21.1)$ & $14(14.9)$ & $22(30.6)$ & 0.02 \\
\hline Length of hospital stay, d, median (range) & $4(1-18)$ & $4(2-18)$ & $4(1-17)$ & 0.6 \\
\hline \multicolumn{5}{|l|}{ Surgical complication $\dagger$} \\
\hline Deep wound infection & $4(2.4)$ & $2(2.1)$ & $2(2.8)$ & 0.8 \\
\hline Wound dehiscence & $2(1.2)$ & $2(2.1)$ & $0(0.0)$ & 0.5 \\
\hline Dural tear & $5(3.0)$ & $3(3.2)$ & $2(2.8)$ & 0.9 \\
\hline Other & $11(6.6)$ & $5(5.3)$ & $6(8.3)$ & 0.4 \\
\hline $\begin{array}{l}\text { Additional surgery within } 2 \mathrm{yr} \text { of index } \\
\text { procedure }\end{array}$ & $16(9.6)$ & $9(9.6)$ & $7(9.7)$ & 1.0 \\
\hline Irrigation and débridement & $7(4.2)$ & $4(4.3)$ & $3(4.2)$ & 1.0 \\
\hline Recurrent same-level stenosis & $4(2.4)$ & $2(2.1)$ & $2(2.8)$ & 0.8 \\
\hline Adjacent-level stenosis & $2(1.2)$ & $2(2.1)$ & $0(0.0)$ & 0.5 \\
\hline Other & $3(1.8)$ & $1(1.1)$ & $2(2.8)$ & 0.4 \\
\hline Death at 2 yr & $6(3.6)$ & $5(5.3)$ & $1(1.4)$ & 0.2 \\
\hline
\end{tabular}




\section{OPEN}

Research

the shorter-wait group v. $84.7 \%$ of those in the longer-wait group, $p=0.5$ ). At 12 months, significantly more patients in the shorter-wait group than in the longer-wait group were

\begin{tabular}{|lcc|}
\hline \multicolumn{3}{|l|}{ Table 3: Mean and median wait times for surgery } \\
\hline Interval & Mean \pm SD, d & Median (range), d \\
\hline $\begin{array}{l}\text { Time from referral from } \\
\text { primary care physician } \\
\text { to initial consultation } \\
\text { with spine surgeon }\end{array}$ & $199 \pm 132$ & \\
\hline $\begin{array}{l}\text { Time from initial } \\
\text { consultation with spine } \\
\text { surgeon to surgery }\end{array}$ & $162 \pm 109$ & \\
\hline $\begin{array}{l}\text { Time from primary care } \\
\text { physician referral to } \\
\text { surgery }\end{array}$ & $361 \pm 173$ & 349 (65-946) \\
\hline
\end{tabular}

Table 4: Pearson product-moment correlation of patient outcome scores at referral and immediately preoperatively with wait time for surgery

\begin{tabular}{|lcc|}
\hline & \multicolumn{2}{c|}{ Time point; $r$} \\
\cline { 2 - 3 } Outcome measure & Referral & $\begin{array}{c}\text { Immediately } \\
\text { preoperatively }\end{array}$ \\
\hline SF-36 PC score & -0.021 & -0.05 \\
\hline SF-36 MC score & $0.233 \dagger$ & $0.192^{*}$ \\
\hline ODI score & $-0.197^{*}$ & $0.223 \dagger$ \\
\hline ZCQ score & -0.050 & $0.16^{*}$ \\
\hline Back pain score & -0.143 & 0.130 \\
\hline Leg pain score & $-0.180^{*}$ & $0.207^{*}$ \\
\hline $\begin{array}{l}\text { Note: } \text { MC }=\text { mental component, ODI }=\text { Oswestry Disability Index, PC }=\text { physical } \\
\text { component, SF-36 = 36-item Short-Form Health Survey, ZCQ }=\text { symptom } \\
\begin{array}{l}\text { severity scale of the Zurich Claudication Questionnaire. } \\
{ }^{*} p<0.05 .\end{array} \\
\dagger p<0.01 .\end{array}$ \\
\hline
\end{tabular}

satisfied with their treatment $(89.3 \%$ v. $75.0 \%, p=0.01)$. However, at 24 months, similar proportions of patients in the shorter- and longer-wait groups were satisfied $(80.9 \% \mathrm{v}$. $75.0 \%, p=0.4)$.

\section{Interpretation}

In this prospective observational study we examined whether a prolonged wait from the time of referral to surgery for lumbar degenerative spinal stenosis was detrimental to outcome. We found that deterioration in outcomes occurred during the waiting period irrespective of the length of wait time, and that patients with a shorter wait experienced greater improvements during the first year after surgery. These findings are of particular relevance to the Canadian publicly funded health care system, in which the median wait times from referral to treatment by a neurosurgeon and by an orthopedic surgeon are 26.6 and 39.6 weeks, respectively. ${ }^{16}$ In a survey of the Canadian Spine Society (completed by $86 \%$ of the membership) performed in 2005 , the total wait time of 24 weeks for elective spinal stenosis surgery was deemed acceptable. ${ }^{17}$ The average wait time in our study, 52 weeks, was more than double this benchmark. Furthermore, patients suffering from the pain and disability associated with lumbar degenerative spinal stenosis would likely deem a much shorter wait time to be acceptable.

We did not confirm our hypothesis that length of wait time would correlate with a decline in function and quality of life during the waiting period. Because our patients were severely affected by spinal stenosis, a "basement effect" may have prevented further deterioration over time. Indeed, preoperative HRQoL was extremely poor when compared with age- and sex-matched Canadian population norms ${ }^{18}$ and was also worse than that reported for other cohorts of patients with lumbar spinal stenosis., ${ }^{4,7}$ Other confounders included the heterogeneity of our patient population and temporizing effects of nonoperative treatment received during the wait. Interestingly, we found poorer initial mental health and function, and higher leg pain scores to be correlated with a shorter

Table 5: Adjusted* mean change in outcome from referral to immediately preoperatively for the 2 wait time groups

\begin{tabular}{|c|c|c|c|}
\hline \multirow[b]{2}{*}{ Outcome measure } & \multicolumn{2}{|c|}{ Wait time; mean change in score (SE)† } & \multirow{2}{*}{$\begin{array}{l}\text { Mean difference in change } \\
\qquad(95 \% \mathrm{Cl})\end{array}$} \\
\hline & Shorter $(\leq 12 \mathrm{mo})$ & Longer (> $12 \mathrm{mo}$ ) & \\
\hline SF-36 PC summary score & $-0.8(0.9)$ & $-1.3(0.9)$ & $0.5(-1.5$ to 2.6$)$ \\
\hline SF-36 MC summary score & $-0.9(1.5)$ & $-1.6(1.6)$ & $0.6(-2.8$ to 4.1$)$ \\
\hline ODI score & $6.6(1.5)$ & $3.9(1.6)$ & $2.7(-0.9$ to 6.2$)$ \\
\hline ZCQ score & $0.2(0.1)$ & $0.2(0.1)$ & $0.01(-0.2$ to 0.2$)$ \\
\hline Back pain score & $0.7(0.5)$ & $0.6(0.6)$ & $0.1(-1.0$ to 1.2$)$ \\
\hline Leg pain score & $0.4(0.3)$ & $0.2(0.4)$ & $0.3(-0.4$ to 1.0$)$ \\
\hline
\end{tabular}


wait time. Furthermore, although the difference was not significant, the average duration of symptoms between onset and consultation was 6 months longer for patients with longer waits than for those with shorter waits. Although the surgeons were blinded to the outcome scores, this finding is likely due to surgeon and referring physician selection bias, whereby surgeons triaged for earlier consultation patients who were perceived to have greater disability and symptom severity.

Wait time was found to have a significant effect on postoperative outcome. Despite poorer preoperative scores (which were controlled for in the postoperative analysis), patients with a shorter wait experienced greater improvements during the first year after surgery. Similarly, in 53 patients undergoing elective posterior lumbar surgery, Braybrooke and colleagues ${ }^{11}$ reported that a longer wait was associated with less improvement in outcome following surgery. In a retrospective study of prospectively followed patients with spinal stenosis treated with both surgery and nonoperative care, Radcliff and colleagues ${ }^{19}$ compared outcome between a patient cohort with symptom duration of 1 year or less versus a cohort with symptom duration greater than 1 year. Those authors found that the outcome following both operative and nonoperative treatment was superior if the duration of preoperative symptoms was 1 year or less. Interestingly, they found that the outcome in patients with degenerative spondylolisthesis was not influenced by symptom duration. They suggested that this was the result of the relatively dynamic nature of spinal stenosis and the preponderance of central canal stenosis compared with the cohort without degenerative spondylolisthesis. In our study, there was no significant difference between wait time groups in the incidence of degenerative spondylolisthesis or the location of spinal canal stenosis.

The greatest differences in improvement in our study were in measures related to mental well-being, spine-specific func-

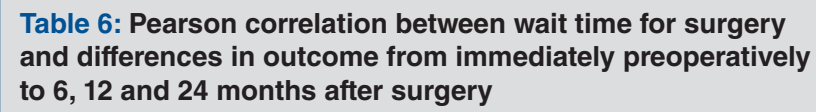

\begin{tabular}{|c|c|c|c|}
\hline \multirow[b]{2}{*}{ Outcome measure* } & \multicolumn{3}{|c|}{ Time point; $r$} \\
\hline & $6 \mathrm{mo}$ & $12 \mathrm{mo}$ & $24 \mathrm{mo}$ \\
\hline $\begin{array}{l}\text { SF-36 PC summary } \\
\text { score }\end{array}$ & -0.079 & 0.063 & 0.067 \\
\hline $\begin{array}{l}\text { SF-36 MC summary } \\
\text { score }\end{array}$ & -0.133 & $-0.224 \ddagger$ & -0.115 \\
\hline ODI score & $0.223 \ddagger$ & $0.205 \dagger$ & 0.064 \\
\hline ZCQ score & $0.200 \dagger$ & 0.093 & 0.156 \\
\hline Back pain score & 0.077 & 0.079 & 0.102 \\
\hline Leg pain score & $0.221 \ddagger$ & 0.160 & 0.054 \\
\hline \multicolumn{4}{|c|}{$\begin{array}{l}\text { Note: } \mathrm{MC}=\text { mental component, } \mathrm{ODI}=\text { Oswestry Disability Index, } \mathrm{PC}=\text { physical } \\
\text { component, } \mathrm{SF}-36=36 \text {-item Short-Form Health Survey, } \mathrm{ZCQ}=\text { symptom } \\
\text { severity scale of the Zurich Claudication Questionnaire. } \\
\text { "Adjusted for baseline score, age, surgeon, duration of symptoms and surgery } \\
\text { type. } \\
+p<0.05 \text {. } \\
\neq p<0.01 \text {. }\end{array}$} \\
\hline
\end{tabular}

tion and leg pain. Although there was significant improvement in these outcomes in both wait time groups, the delayed recovery of function and mental health observed among those with longer waits likely reflects the advanced deconditioning that occurred secondary to prolonged immobility from spinal stenosis. Interestingly, the magnitude of improvement in the SF-36 physical component summary score did not correlate with wait time or differ between wait time groups despite the difference observed for Oswestry Disability Index scores. This is likely due to 2 factors. First, the comorbidities common to many patients with spinal degenerative disease have a negative impact on the improvement in outcome scores following surgery, particularly on a general measure of quality of life such as the SF-36 physical component summary. ${ }^{20-22}$ Second, Oswestry Disability Index and leg pain measures are recognized to be much more sensitive measures of response to spine surgery than is the SF-36 physical component summary, as lumbar degenerative spinal stenosis is a slow, progressive disease that may not be detected by the SF-36 physical component summary. ${ }^{23}$

The preoperative duration of spinal stenosis symptoms as a predictor of postoperative outcome is controversial. ${ }^{24}$ Some investigators have found that symptom duration greater than 1 year is associated with a poorer surgical outcome, ${ }^{19,25,26}$ whereas others have refuted this association. ${ }^{27,28}$ However, several of these studies were retrospective, subgroup post-hoc analyses that relied on patient recall to define the preoperative symptom duration. In contrast, our study had a prospective design and included the entire spectrum of wait times commonly experienced in Canada, from the time of referral to surgery.

\section{Limitations}

We did not randomly assign our patients to a shorter or longer wait for surgery. Therefore, surgeon and referring physician bias, patient expectation, severity of the primary disease and secondary comorbidities were potential cofounders in our design. We controlled for some of these potential biases, such as the difference between each surgeon's approach and surgical wait list, and the outcome scores at presentation, in our analysis. Furthermore, we performed multiple comparisons, which theoretically may have increased the risk of a type 1 error. With respect to the generalizability of our findings, spine surgeons will recognize that the fusion rate in our study is higher than would be expected for a cohort of patients with spinal stenosis treated today. This higher fusion rate is based on our previous practice of performing fusion in almost all patients with degenerative spondylolisthesis or severe foraminal stenosis as a result of disc height loss. The current trend toward using more time-efficient techniques of anatomy-sparing selective decompression without fusion will likely help decrease surgical wait times.

\section{Conclusion}

Patients awaiting surgery for lumbar degenerative spinal stenosis experienced deterioration in function and HRQoL 


\section{OPEN}

Research

\begin{tabular}{|c|c|c|c|}
\hline \multirow[b]{2}{*}{ Time point; outcome measure } & \multicolumn{2}{|c|}{ Wait time; mean change in score (SE)† } & \multirow{2}{*}{$\begin{array}{l}\text { Mean difference in change } \\
\qquad(95 \% \mathrm{Cl})\end{array}$} \\
\hline & Shorter $(\leq 12 \mathrm{mo})$ & Longer (> $12 \mathrm{mo}$ ) & \\
\hline \multicolumn{4}{|l|}{$6 \mathrm{mo}$} \\
\hline ODI score & $-26.8(2.7)$ & $-18.2(2.7)$ & $-8.5(-14.7$ to -2.4$)$ \\
\hline ZCQ score & $-1.6(0.2)$ & $-1.3(0.2)$ & $-0.3(-0.6$ to 0.05$)$ \\
\hline Back pain score & $-5.0(0.6)$ & $-4.7(0.6)$ & $-0.4(-1.6$ to 0.8$)$ \\
\hline Leg pain score & $-6.2(0.6)$ & $-4.9(0.6)$ & $-1.4(-2.6$ to -0.1$)$ \\
\hline ODI score & $-30.2(2.5)$ & $-20.8(2.5)$ & $-9.3(-15.1$ to -3.6$)$ \\
\hline ZCQ score & $-1.6(0.2)$ & $-1.5(0.2)$ & $-0.2(-0.5$ to 0.2$)$ \\
\hline Back pain score & $-4.9(0.6)$ & $-4.3(0.7)$ & $-0.5(-1.9$ to 0.7$)$ \\
\hline Leg pain score & $-6.8(0.6)$ & $-5.2(0.7)$ & $-1.6(-3.0$ to -0.3$)$ \\
\hline \multicolumn{4}{|l|}{$24 \mathrm{mo}$} \\
\hline SF-36 PC summary score & $10.6(1.7)$ & $11.2(1.9)$ & $-0.7(-4.8$ to 3.3$)$ \\
\hline SF-36 MC summary score & $9.6(1.8)$ & $5.9(1.9)$ & $3.7(-0.6$ to 8.0$)$ \\
\hline ODI score & $-27.1(2.4)$ & $-22.2(2.6)$ & $-4.9(-10.6$ to 0.9$)$ \\
\hline ZCQ score & $-1.4(0.2)$ & $-1.2(0.2)$ & $-0.2(-0.6$ to 0.1$)$ \\
\hline
\end{tabular}

during the waiting period, but the magnitude of the decline was not influenced by wait duration. However, longer waits (12 months or more) were associated with a delay in recovery during the first year after surgery. The wait times in our study reflect the reality faced by spinal surgeons and patients in Canada today. Our results suggest that strategies to reduce wait times are needed. Such strategies are slowly being implemented and include education and quality-based guidelines for primary care providers, multidisciplinary assessment and treatment clinics for patients with acute or chronic low back pain, and use of cost- and time-efficient treatments including surgical options.

\section{References}

1. Battié MC, Jones A, Schopflocher DP, et al. Health-related quality of life and comorbidities associated with lumbar spinal stenosis. Spine f 2012;12:189-95.

2. Fanuele JC, Birkmeyer NJO, Abdu WA, et al. The impact of spinal problems on the health status of patients: Have we underestimated the effect? Spine 2000; 25:1509-14.

3. Hansson T, Hansson E, Malchau H. Utility of spine surgery. A comparison of common elective orthopaedic surgical procedures. Spine 2008;33:2819-30.

4. Weinstein JN, Tosteson TD, Lurie JD, et al. Surgical versus nonoperative treatment for lumbar spinal stenosis: four-year results of the Spine Patient Outcomes Research Trial (SPORT). Spine 2010;35:1329-38.
5. Lurie JD, Tosteson TD, Tosteson A, et al. Long-term outcomes of spinal stenosis. Eight year outcomes of SPORT. Spine 2015;40:63-76.

6. Weinstein JN, Lurie JD, Tosteson TD, et al. Surgical compared with nonoperative treatment for lumbar degenerative spondylolisthesis. $\mathcal{F}$ Bone foint Surg Am 2009;91:1295-304.

7. Malmivaara A, Slatis P, Heliovaara M, et al. Surgical or nonoperative treatment for lumbar spinal stenosis? A randomized controlled trial. Spine 2007;32: $1-8$.

8. Atlas SJ, Keller RB, Wu YA, et al. Long-term outcomes of surgical and nonsurgical management of lumbar spinal stenosis: 8 to 10 year results from the Maine Lumbar Spine Study. Spine 2005;30:936-43.

9. Rampersaud YR, Wai EK, Fisher CG, et al. Postoperative improvement in health-related quality of life: a national comparison of surgical treatment for focal (one- to two-level) lumbar spinal stenosis compared with total joint arthroplasty for osteoarthritis. Spine 7 2011;11:1033-41.

10. Mokhtar SA, McCombe PF, Williamson OD, et al. Health-related quality of life: a comparison of outcomes after lumbar fusion for degenerative spondylolisthesis with large joint replacement surgery and population norms. Spine 7 2010;10:306-12

11. Braybrooke J, Ahn H, Gallant A, et al. The impact of surgical wait time on patient-based outcomes in posterior lumbar spinal surgery. Eur Spine 7 2007; 16:1832-9.

12. Grevitt M, Khazim R, Webb J, et al. The Short Form-36 health survey questionnaire in spine surgery. 7 Bone foint Surg Br 1997;79:48-52.

13. Roland M, Fairbank J. The Roland-Morris Disability Questionnaire and the Oswestry Disability Questionnaire. Spine 2000;25:3115-24.

14. Stucki G, Daltroy L, Liang MH, et al. Measurement properties of a self-administered outcome measure in lumbar spinal stenosis. Spine 1996;21:796-803.

15. Hudak PL, Wright JG. The characteristics of patient satisfaction measures. Spine 2000;25:3167-77. 
16. Barua B, Esmail N. Waiting your turn: wait times for health care in Canada, 2012. Vancouver: Fraser Institute; 2012. Available: www.fraserinstitute.org/sites/ default/files/waiting-your-turn-2015.pdf (accessed 2015 Jan. 5).

17. A clinical perspective on appropriate wait-times for elective spinal surgery. Spinal Columns 2006;Vol. 6, No. 2. Available: http://spinecanada.ca/newsletter2006-volume-6-number-2/ (accessed 2014 Aug. 28).

18. Hopman WM, Towheed T, Anastassiades T, et al. Canadian normative data for the SF-36 health survey: Canadian Multicentre Osteoporosis Study Research Group. CMA7 2000;163:265-71.

19. Radcliff KE, Rihn J, Hilibrand A, et al. Does the duration of symptoms in patients with spinal stenosis and degenerative spondylolisthesis affect outcomes? Analysis of the Spine Outcomes Research Trial. Spine 2011;36:2197-210.

20. Slover J, Abdu WA, Hanscom B, et al. The impact of comorbidities on the change in Short-form 36 and Oswestry scores following lumbar spine surgery. Spine 2006;31:1974-80.

21. Garratt AM, Klaber Moffett J, Farrin AJ. Responsiveness of generic and specific measures of health outcome in low back pain. Spine 2001;26:71-7.

22. Stucki G, Liang MH, Fossel AH, et al. Relative responsiveness of condition specific and generic health status measures in degenerative lumbar spinal stenosis. 7 Clin Epidemiol 1995;48:1369-78.

23. DeVine J, Norvell DC, Ecker E, et al. Evaluating the correlation and responsiveness of patient-reported pain with function and quality-of-life outcomes after spine surgery. Spine 2011;36(21 Suppl):S69-74.

24. Aalto TJ, Malmivaara A, Kovacs F, et al. Preoperative predictors for postoperative clinical outcome in lumbar spinal stenosis. Spine 2006;31:E648-63.

25. Athiviraham A, Wali ZA, Yen D. Predictive factors influencing clinical outcome with operative management of lumbar spinal stenosis. Spine 7 2011;11:613-7.

26. Aalto T, Sinikallio S, Kroger H, et al. Preoperative predictors for good postoperative satisfaction and functional outcome in lumbar spinal stenosis surgery a prospective observational study with a two-year follow-up. Scand 7 Surg 2012;101:255-60.

27. Amundsen T, Weber H, Nordal HJ, et al. Lumbar spinal stenosis: Conservative or surgical management? A prospective 10-year study. Spine 2000;25:1424-35.
28. Spratt KF, Keller TS, Szpalski M, et al. A predictive model for outcome after conservative decompression surgery for lumbar spinal stenosis. Eur Spine 7 2004;13:14-21.

Affiliations: Division of Orthopaedics, Department of Surgery, Schulich School of Medicine and Dentistry (Bailey CS, Gurr, Bailey SI, Taylor), Western University; London Health Sciences Centre (Bailey CS, Gurr, Bailey SI, Taylor, Rosas-Arellano, Tallon, Urquhart); and Lawson Health Research Institute (Bailey CS, Rosas-Arellano, Tallon, Bureau, Urquhart), London, Ont.

Contributors: Christopher Bailey conceived and designed the study, secured funding, recruited patients, managed and interpreted the data and prepared the manuscript. Jennifer Urquhart, Patricia Rosas-Arellano and Corinne Tallon acquired the data and contributed to drafting the manuscript. Jennifer Urquhart conducted statistical analysis and revised the manuscript. Yves Bureau assisted with study design, conducted statistical analysis and revised the manuscript. Kevin Gurr, Stewart Bailey and David Taylor assisted with study design, supervised the recruitment of patients and management of data, and revised the manuscript. All of the authors gave final approval of the version to be published and agreed to act as guarantors of the work.

Funding: No funding was received specifically for this study. General institutional funding support for research endeavours by the London Spine Centre is received from Medtronic Canada, Stryker Canada and Synthes Canada.

Supplemental information: For reviewer comments and the original submission of this manuscript, please see www.cmajopen.ca/content/4/2/ E185/suppl/DC1 